\title{
Biosensors: Their Fundamentals, Designs, Types and Most Recent Impactful Applications: A Review
}

\author{
Jazib Ali ${ }^{1 *}$, Jawayria Najeeb² ${ }^{2}$ Muhammad Asim Ali ${ }^{1}$, Muhammad Farhan Aslam ${ }^{1}$ and Ali Raza ${ }^{1}$
}

${ }^{1}$ National Institute for Biotechnology and Genetic Engineering (NIBGE), Faisalabad, Pakistan

${ }^{2}$ Institute of Chemistry, University of the Punjab, Lahore (PU), Pakistan

\begin{abstract}
Biosensors are the devices that capture the biological signal and convert it into a detectable electrical signal. It involves the combination of biological entities like DNA, RNA, and proteins/enzymes to the electrochemical transducers in order to detect and observe certain biological analytes like antibody-antigen interaction. Several types of biosensors have been known that have been successfully employed in the fields of environment, biomedical and food industries to detect and remove certain contaminants, weather non-living or living entities. Amperometric, Optical, Surface Plasmon Resonance, enzymatic, DNA, Phage, and bacterial sensors are the common sensors being employed today. These biosensors can be used for the detection of the broad spectrum of biological analytes and have shown greater responses and success in medical laboratories, food bioanalysis, microbial detection etc. Detection of the lower or higher limits of glucose in body, microbial invasion in body and food, heavy metals detection in soil, water and air-borne microbes, pesticides in water and soil and various harmful chemicals produced by body, can be easily and timely monitored with high precision using the different types of biosensors with few modifications.
\end{abstract}

Keywords: Transducer; Bioanalyte; Biosensors; Phage-sensor; Surface Plasmon Resonance (SPR) sensor; Amperometric sensor; Conductimetric sensor

\section{Introduction}

\section{Sensors; their fundamentals and categorization}

The word "sensor" find its origin from the Latin word "sentire" which basically means 'to identify' anything. By hearing this word sensor, the foremost thing that springs into our minds is the concept of basic five human senses: ophthalmoception, audioception, gustaoception, olfacception and tactioception. The working mechanism of these senses is generalized as a) reception of input signal by the sensory cells because of external stimuli b) conduction of data towards the brain for interpretation as neurological impulses c) receptors respond to the stimulus as per instructed by the interoperating center. With this brief explanation of sense, more methodical and technical definition for sensor could be established which is as follows; it is a device that obtains and responds to stimulus and signals originated from the environment [1].

In terms of categorization, physical sensors and chemical sensors are the two most fundamental and widely opted classes of sensors. The main idea behind this first classification also arises from scrutinizing the human senses. Since the common working mechanism behind the sense of hearing, touch and sight is to respond on the external physical stimuli (i.e., acoustic waves, pressure and electromagnetic radiations respectively), hence any sensing device that provide response to the physical property of the medium was termed as physical sensor [2]. Similarly, the senses of taste and smell respond to chemical stimuli of odor and particular palate flavor of the molecules; any sensing device that can transform chemical information of the system into analytically analyzable signals was included into the division of chemical sensors [3]. The comprehensive pictorial description of the customary sensor is given in Figure 1. Sensor contains specific reacting site that could respond to a specific sort of an analyte in the medium. Analyte/ stimulus triggers a chemical interaction at the site which initiates the conversion of information into electrical signal. Electrical signal is then transmitted to another unit, the processing unit that further carries out the detection response [4]. Technically, the sensor is composed of two parts i.e., receptor and transducer. Receptor receives the physical/ chemical stimulus and transmutes this information in the form of electrical energy while transducer performs the function of transducing this energy into valuable analytical signal which can further be analyzed and presented in an electronic form [5] (Figure 1).

Numerous other classes including magnetic sensors [6-8],

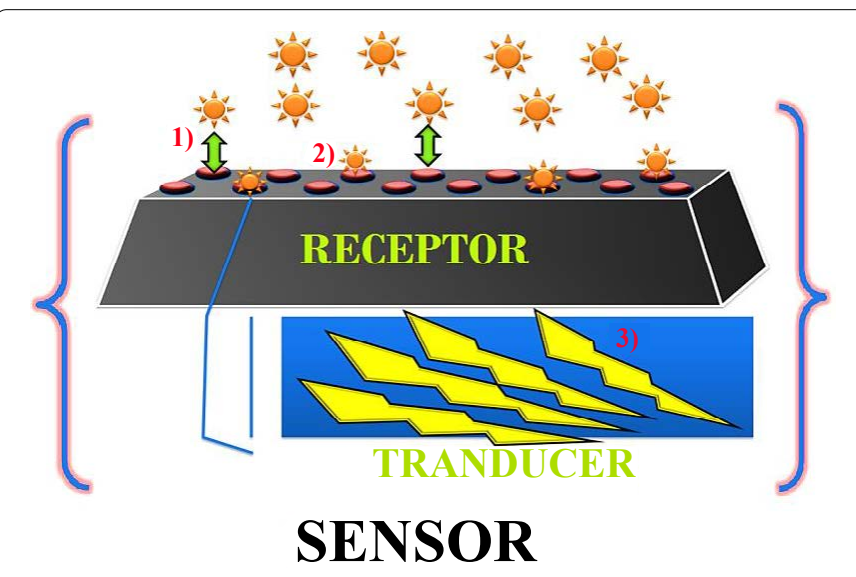

Figure 1: Diagram representing various processes occurring in sensors 1) analyte is getting attracted to the receptor sites 2) chemical interaction between analyte generating electrical signal 3) Transducer transducing the electrical signal to processor.

*Corresponding author: Jazib Ali, National Institute for Biotechnology and Genetic Engineering (NIBGE), Faisalabad, Pakistan, Tel: +923465449709; E-mail: jazibali10@yahoo.com

Received November 24, 2016; Accepted January 18, 2017; Published January 28, 2017

Citation: Ali J, Najeeb J, Ali MA, Aslam MF, Raza A (2017) Biosensors: Their Fundamentals, Designs, Types and Most Recent Impactful Applications: A Review. J Biosens Bioelectron 8: 235. doi: 10.4172/2155-6210.1000235

Copyright: ( 2017 Ali J, et al. This is an open-access article distributed under the terms of the Creative Commons Attribution License, which permits unrestricted use, distribution, and reproduction in any medium, provided the original author and source are credited. 
thermometric sensors [9-11], optical sensors [12-14], radiation detecting sensors [15-17], electrical sensors [18-20] and electrochemical sensors $[21,22]$ etc. have been extensively reported in literature by several researchers. The basis for this categorization is anything but universal. Mode of reception, field of application, particular given analyte that is detected, measuring method and so on are the few direct approaches that has been associated with the essence of classification in this matter. Since no hard line has been drawn by IUPAC regarding the classification of sensors, it could be customized that sensors are the devices that can reversibly and selectively evaluate the amount of the analyte species molecules by amplifying the acquired signal from the chemical interaction between the receptor sites and the analyte without requiring any other analytical instruments or chemical mixtures for the detection.

\section{Biosensors}

Biosensors, a hybrid of physical and chemical sensing technique, is among one of the recently described class of the sensor. IUPAC provide recognition to this type of sensors only some seventeen years prior to today [1]. In principle, biosensors are receptor-transducer based tool which could be employed for interpreting the biophysical or biochemical property of the medium. Moreover, the most intriguing character that sets this type of sensors apart from others is the presence of biological/organic recognition element which enables the detection of particular biological molecules in the medium [23]. Development of biosensors brought a new era of advancement in science. Technically speaking, biosensing is a phenomenon that withholds set techniques for the production of an accessible detection signal of interaction between biological molecules (such as a domain of protein and another molecule or analyte of interest like any other small molecule, another protein or an enzymatic activity). Such molecular device that enables sensing of these molecular interactions is called biosensors [24]. Another consideration that fascinates lots of researchers regarding exploiting this particular field for exploration is its versatility. It is an interdisciplinary technology and involves the collaborative efforts of engineering, microbiology, physics, chemistry, biology, biotechnology and so on [25].

Biosensors have been widely used in different scientific disciplines due to their outstanding results. Medically, biosensors can be used for accurate and precise detection of tumors, pathogens, elevated blood glucose levels in diabetic patients and other toxins etc. Fluorescence producing biosensors that are encoded by genes have great importance for researchers to study and analyze the complex chemical processes going on in the cells and these kinds of biosensors could be used to target some specific locations in the cell and it can also be expressed in specific cells of an organism. The long term incorporation of any specific substance into the host cells could also be achieved through these biosensors [26]. In case of food industry, biosensors could be linked to the detection of gasses released from spoiled food, detection of food contamination or for checking and minimizing the growth of bacteria or fungus in fresh food [27]. From environmental point of view, these biosensors could be enhanced to detect pollution in air and presence of any pathogens, heavy metals etc. [28]. In military defense systems, they can be used to detect the presence of any harmful biological materials that would otherwise remain undetectable and cause death. In this case mostly the biosensors can be employed to detect the bioterrorist attacks like the intentional use of the biological entities like Bacillus anthracis, Ebola, hepatitis C viruses etc. [29].

This advancing technology collects a humungous amount of literature every year. The numbers of the reported articles falling under this label are gigantic. Henceforth, an attempt should be made in this regard for organizing the already present literature in a presentable way so that the upcoming researchers who want to reconnoiter this field of biosensing could have an effective guideline at hand to follow. Here in, efforts have been invested into providing the critical analysis of the most recent advancements in biosensing technology acquired in the span of recent years and case studies with specific fields and quite high citation numbers have been compiled to produce a versatile review of this field. This review will be beneficial for the multitude of interdisciplinary personals such as physicists, biologists, chemists, environmentalists and so on.

\section{Structure of the review}

The section 2 of this review entails the fundamentals and classification along with the detailed discussion of the designs and structural configuration information regarding this vast field of biosensors. After the development of understanding regarding the structural hierarchies of the biosensors, specific case studies associated with particular field of applications have been discussed under the section 3. Pictorial descriptions are also provided where required and concluding remarks are presented at the end of the review.

\section{Fundamentals of Biosensors}

\section{Architectural design}

This first biosensor was a potentiometric enzyme based electrode that was invented for the detection and measurement of glucose in any medium [30]. However, analysis of recent studies indicate that nowa-days a considerable amount of energy has been spent in reducing the size and making the laboratories economically stable towards the development of portable, small-sized/nanosized and multi-functional biosensors [31]. Nonetheless, the basic fundamentals of the biosensors remained the same i.e., a bioelement and sensor element. Bioelement is basically any organic body which should essentially detect any particular analyte from the medium of interest while remaining irresponsive towards any other potentially inquisitive/interfering species. While sensing element consists of the signal transducing portion of the biosensor which could be in the form of any magnetic, optical, electrical or electrochemical etc. transducing mechanism [32]. Elaboration of these two components is given in Figure 2.

Despite this ever-increasing flexibility shown by the scientists

\begin{tabular}{|c|c|c|}
\hline \multirow[t]{13}{*}{ COMPONENTS } & \multirow{6}{*}{ 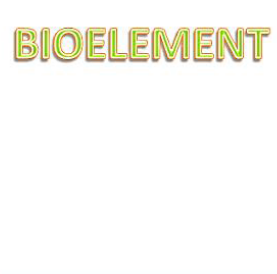 } & POLYSAGCHARIDE \\
\hline & & MICROEUAL \\
\hline & & NUCUEICACID \\
\hline & & TISSUE \\
\hline & & ENZYME \\
\hline & & ANTIEODY \\
\hline & \multirow{7}{*}{$\begin{array}{l}\text { SENSQR } \\
\text { ELEMENT }\end{array}$} & VIScosity \\
\hline & & TEMPERATURE \\
\hline & & MASS \\
\hline & & ELECTRICAL CURRENT \\
\hline & & ELECTRICAL POTENTIAL. \\
\hline & & ELECTRIC IMPEDANCE \\
\hline & & EM RADIATIONS \\
\hline
\end{tabular}

Figure 2: Generally employed bioelements and sensor elements in biosensors 
in the selection of various substances/factors as the components of biosensors, the requisite requirements including rapid responding ability, reliability, portability, productivity and long-lasting stability have been essentially stayed the same. The crucial factors that should be considered during the engineering of high performance biosensors are summarized as follows; a) immobilization/fabrication of bioanalyte in its native configuration, $b$ ) high accessibility of the reception sites to the species of interest and c) effectual adsorption of the analyte to the employed support [33,34]. These demands should be actively addressed when developing the design of biosensors.

Bio-element and senor element coupling: For the effective incorporation of the biological/organic recognition element into the sensor, several phenomena have been proposed. In here, light has been shed on only four major coupling mechanisms that have been widely opted for acquiring the required purpose; a) physical adsorption encapsulation, b) membrane immobilization, c) covalent amalgamation and d) matrix entrapment. In membrane entrapment, organic element is imbedded into the some particular semi-permeable membrane which is directly placed over the sensor element. In this type, membrane performs as a separating phase between organic element and that of the analyte [35]. If the coupling mechanism involves the use of physical intermolecular forces (hydrophilic/hydrophobic forces, Van Der Waals forces, ionic forces etc.) for the attachment of the bioelement to the sensor then this sort of coupling is termed as the physical adsorption immobilization [36]. Similarly, if any porous substances like sol or gel matrixes are employed as the restricting medium for the biological element and this matrix encapsulation forms direct link with the sensor element, then it is named as matrix immobilization [37]. If the bioelement is directly attached to the sensor by covalent interactions then this type is labeled as covalent coupling [38]. Figure 3 represents the basic idea behind this different sort of coupling types.

\section{Classification of biosensors}

For classifications, several approaches can be utilized [1,39].

a) Depending upon the used transduction principle, biosensors could be distributed into groups of electrochemical, mass dependent, optical, radiation sensitive and so on [40].

b) Enzyme, nucleic acid, proteins, saccharides, oligonucleotides, ligands etc. are the various sets of biosensors which could be acquired if bioelement is considered as the basis of categorization [41]

c) Following the type of detected analyte, classes of DNA, glucose, toxins, mycotoxins, drugs or enzymes based biosensors could be achieved [42].

Here in, an unspecified division has been followed as per requirement of the review. However, detailed elaboration regarding these classes has been provided where required in the next application section.

\section{Most Recent Biosensors Applications}

Till date, this growing field of biosensors has almost got quite strong hold in every walk of life. Here, the most recent developments and improvements of this biosensing discipline are studied in the basics fields of agriculture, biomedicine, food and environmental studies. Specific impactful case studies in this regard are reviewed in this section.

\section{Biomedical applications}

Most of the biosensors reported in the past six years are found to be based on the phenomena of molecular interactions which are essentially employed in various forms at different scales. Extensive literature scrutiny indicated that enzyme-substrate sensors are one of most generally followed types in this regard. Pertinacious catalytic enzymes exhibit significantly extraordinary selectivity as well as specificity with respect to the substrates. At first, reversible reaction between the enzyme and specific analyte generates the complex that is further responsible for creating the desired product. Catalyst also gets regenerated in its parent configuration as a side-product [41]. Several analyte that possess high nutraceutical value could be detected and analyzed by using this interaction type. In here, biosensors are orderly presented with respect to the essential analyte that gets detected.

Glucose: Owing to the enhancing number of personals getting effected by the diabetes mellitus every year, the demand for engineering point of use glucose sensing technologies have also grown and with it the reports of biosensors being used for this purposes. The enzymes of glucose oxidases (G-ox) and glucose dehydrogenases are the two
A)



B)

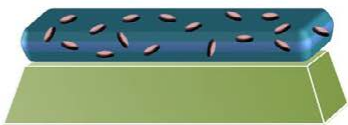

\section{BIOELEMENT-SENSOR ELEMENT COUPLING MECHANISMS}

C)

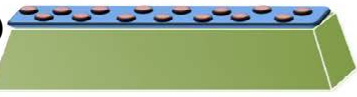

D)

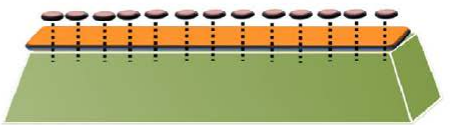

KEY: OBIOELEMENT SENSOR ELEMENT $\longrightarrow$ SEPARATING MEDIUM
SEMIPERMEABLE MEMBRANE

Figure 3: Various coupling mechanisms: A) Covalent fabrication, B) Matrix immobilization, C) Membrane encapsulation, D) Physical adsorption fabrication. 
conventionally utilized enzymes that are effectively employed at quite large scale for glucose detection [43-45]. A case reported by Binesh and co-workers evidently presents the use of G-ox at its best. They documented a facile and single stepped methodology for the preparation of graphene-(G-ox) biocomposite which displayed excellent sensitivity of $1.85 \mu \mathrm{AmM}^{-1} \mathrm{~cm}^{-2}$ over the glucose concentration range of $0.1-27$ $\mathrm{mM}$. For studying the potential bioapplication of the engineered biosensor, a prototype display was also performed over human serum and results were reproduced with quite high precision that have already been detected by using conventional method of glucose level evaluation. Moreover, it was also tested against interfering species that usually exists in the biological systems. The biosensor was found to be irresponsive towards their presence and no significant effect was measured on its performance [44].

Another thing that has significantly and successfully penetrated in this field is the use of nanoparticles (Nps) as a sensing medium. A more compatible system for evaluation of blood-glucose was proposed by Zheng and his associates. They used immobilized gold Nps and G-ox composite for acquiring the same aforementioned purpose. Quite greener approach was opted for engineering this biosensor as membrane removed from chicken egg shells were used to serve as the fabricating media for the Nps. This membrane based composite was then wrapped over the oxygen electrode and the whole assembly was utilized as biosensor [46]. Advanced glucose sensor having the ability to quantify the glucose from $0.5 \mu \mathrm{M}$ up to the level of $34 \mathrm{mM}$ was devised by Yang et al. They utilized core-shell assembly containing polypyrrole Nps and incorporate it over magnetically active carbon electrode to acquire the sensor. Highly economical response time of $6 \mathrm{~s}$ and good stability were found to the two basics appeals of this core-shell based biosensor [47-53]. The basic studies overview regarding enzyme based biosensors is given in Table 1 .

It is imperative to comment regarding the extent of impact of fluctuating oxygen content over the G-ox based sensors. As the G-ox based sensors directly depends over the $\mathrm{O}_{2}$ as an electron accepting specie during sensing, so condition of oxygen deficit should always be considered beforehand as it could minimize the upper linearity limit and response time as well. For avoiding this difficulty, other alternative enzymes, particularly glucose dehydrogenase (G-dh), could also be utilized for biosensing [54]. Apart from these direct methodologies, an interesting indirect practice has been reported by the Yan and his group who provided the prototype of needle-biosensor which could be employed for the detection of glucose in tears of human beings. The tear glucose concentration was then co-related with the glucose level in blood serum as it has been also reported that the patients suffering from the illness of diabetes have very much higher concentration of glucose in their tears as compared to the normal person [54,55]. This fascinating idea however still requires lot of amendments before finding its industrial use at commercial level.

\section{Applications in tissue engineering}

In tissue engineering, biosensors plays immensely significant role in the applicability of the various applications, such as manufacturing "organ specific onchips" and maintaining the 3-D integrity and configuration of the cell cultures where the fate of tissues/cells is directly associated with the content of small biomolecules (adenosine, glucose, hydrogen peroxides etc.) in the medium. Living metabolic cells are quite eminent for transmuting and transferring numerous signals (physical/chemical) in and out of the medium. These signals could be in any form such as variation in ionic concentration, $\mathrm{pH}$, protein content, oxygen ingestion etc. Hence, monitoring these incoming/outgoing analyte could be directly utilized for acquiring real time insights of the cell [56].

DNA, nucleic acids, genes: Several basic fields related to the research have direct link to the genetic diagnostics and DNA encoding. Hence, biosensors application with respect to nucleic acids is undeniably significant. Typically, a DNA specified sensor comprises of following three processes; a) incorporation of probes over the film of substrate, b) contact with the required DNA sequence through analogue bases pairing and c) read out in the form of analytically useful signal generated from the chemical signal produced as a result of bases interaction [57]. DNA concentration, generally up to $10^{-8}$, could be detected by electrical [58], optical [59] and electrochemical methods [60]. Use of nanomaterial and quantum dots is also excessively finding its uses here. A highly sensitive DNA electrochemical biosensor developed by using dendritic gold Nps was reported by Li et al. This biosensor showed the DNA recognition ability up to $1 \mathrm{fM}$ under the concentration limitation of (1fM-1nM) [61].

An impressive foot regarding the DNA biosensing was achieved by Chen et al. who synthesized ultra-sensitive sensor fundamentally based over nuclease mediated highly targeted recycling of DNAzyme for the electrochemical detection of oral cancer from the saliva secretions. With the help of this sensor, quantization up to the $0.02 \mathrm{fM}$ of the targeted DNA was possible. Furthermore, gene mutation up to the single basepair mismatch detection was also acquired through this sensor. These aforementioned characters along with the operation and maintenance conveniences and low engineering cost make this biosensor a promising

\begin{tabular}{|c|c|c|c|c|c|}
\hline Biosensor & Linear range & Response time & Detection limit & $\begin{array}{l}\text { Sensitivity } \\
\mu A \mathbf{M M}^{-1} \mathbf{c m}^{-2}\end{array}$ & References \\
\hline Graphene-(G-ox) & $0.1-27 \mathrm{mM}$ & $<5 \mathrm{~s}$ & --- & 1.85 & [44] \\
\hline PB/MWNTs-(G-ox)-CS-ICPTES & $0.25 \mu \mathrm{M}-1.3 \mathrm{mM}$ & $<10 \mathrm{~s}$ & $7.5 \mu \mathrm{M}$ & 5.94 & [43] \\
\hline AuNPs-(G-ox)-MWCNTs-PVA & $0.5-8 \mathrm{mM}$ & $<10 \mathrm{~s}$ & $0.2 \mathrm{mM}$ & 16.6 & {$[45]$} \\
\hline PdNPs/CS-GR-(C-ox)/GC & $1 \mu \mathrm{M}-1 \mathrm{mM}$ & $<10 \mathrm{~s}$ & $0.2 \mu \mathrm{M}$ & 31.2 & [48] \\
\hline CS-Fc/GO/(G-ox) & $0.02-6.78 \mathrm{mM}$ & $<5 \mathrm{~s}$ & $7.6 \mu \mathrm{M}$ & 10 & [49] \\
\hline (G-ox)-AuNPs/ESM & $8.3 \mu \mathrm{M}-0.96 \mathrm{mM}$ & $<30 \mathrm{~s}$ & $3.50 \mu \mathrm{M}$ & 9.421 & [46] \\
\hline Nafion/ZnO-HNSPs/(G-ox)/GCE & $0.005-13.15 \mathrm{mM}$ & $<5 s$ & $1.0 \mu \mathrm{M}$ & 65.82 & {$[50]$} \\
\hline (G-ox)/ (AuNPs/MWCNT) & $20 \mu \mathrm{M}-10 \mathrm{mM}$ & $<3 s$ & $2.3 \mu \mathrm{M}$ & 19.27 & {$[51]$} \\
\hline (G-ox)-CS/AgNWs/GCE & $10 \mu \mathrm{M}-0.8 \mathrm{mM}$ & $<10 \mathrm{~s}$ & $2.83 \mu \mathrm{M}$ & --- & {$[52]$} \\
\hline (G-ox)/CeO ${ }_{2}$ NRs/ITO & $2-26 \mathrm{mM}$ & $1-2 \mathrm{~s}$ & $100 \mu \mathrm{M}$ & 0.165 & [53] \\
\hline $\mathrm{PPF} /(\mathrm{G}-\mathrm{dh}) / \mathrm{PT} / \mathrm{CNT} / \mathrm{PPF} / \mathrm{Au}$ & $4.9-19 \mathrm{mM}$ & $5 \pm 1 \mathrm{~s}$ & $0.12 \mathrm{mM}$ & $5.1 \pm 0.9$ & [54] \\
\hline Nafion/(G-dh)-bacteria/CNT & $50-800 \mu \mathrm{M}$ & --- & $4 \mu \mathrm{M}$ & --- & [55] \\
\hline
\end{tabular}

Enzymes: (G-ox): Glucose oxidases; (G-dh): Glucose dehydrogenases

Table 1: Enzyme based biosensors employed for glucose detection. 
candidate for oral cancer detection at the commercial level [62]. Yang et al. devised an altered graphene electrode which possesses the ability to chemically bind with ssDNA and generate Volta-metric signal for its counter analogue DNA for detection [63]. Several other reported biosensors for the DNA sequence detection are given as follows [64-67].

Hydrogen peroxide $\left(\mathrm{H}_{2} \mathrm{O}_{2}\right)$ : Measuring the $\mathrm{H}_{2} \mathrm{O}_{2}$ content with accuracy and reproducibility are of supreme prominence both clinically as well as in tissue engineering. In humans, its content is a direct indicative of the oxidative stress faced by cell or hypoxic conditions of tissues. As of now, various analytic techniques like titration, electrochemistry and photocatalysis could be employed for $\mathrm{H}_{2} \mathrm{O}_{2}$ recognition [68]. High concentration of this highly unstable specie in any biological system is highly injurious and needed to be avoided as it cause cytotoxicity in humans and also to a large variety of plants, animals as well as bacteria [69]. In the field of tissue

Engineering, generally employed methods for $\mathrm{H}_{2} \mathrm{O}_{2}$ quantification are mostly electrochemical in nature and poses several difficulties (poor detection, low sensitivity, less portability and applicability issues on the organic system) to the user [56]. Enzyme based biosensing have recently found its footing here too owing to the manufacturing of the biosensors with quite high stability and accuracy [70,71]. This prevailing interest in this type could be attributed to the manufacturing of steady sensor assembly that possess fully functionalized binding sites of the pertinacious enzyme even after its deposition over some rigid electrode/surface [72]. Immobilization medium includes, but not confined to, quantum dots [73], polymers [74] and nanostructures [75]. Recent advances in this regard are summarized in Table 2.

\section{Applications in food industry}

In the food based industry worldwide, science has contributed maximally to benefit this field in order to meet the consumer demands of fresh and healthy foods. In order to ensure the safety of processed foodstuffs, specific methods have been adopted by the food industries of to sort out the problems leading to food spoilage and detection and destruction of such chemicals or biological agents that are responsible for the spread of some serious health related problems [76,77]. Biosensors being target specific, highly sensitive and quickly responsive would be helpful in that regard to enable us to determine the cause of chemical activities that leads to the food spoilage, not only the canned and industrial food products, same case applies to the food crops too. In order to measure the extent of freshness of food, we must have to evaluate the quality of food first and to do so one has to be expert in judging quality related traits of food materials that are under evaluation. According to Luong, Bouvrette [78], 1.5$2 \%$ of the total expenses are required by every food industry to spend on the quality evaluation of foodstuffs. All kinds of food products, either processed or unprocessed, can be initially tested by on spot visualization, other quality testing attributes like touch, taste and smell can later be employed upon which final decisions can be made. One of the fundamental principles of biosensors working depends upon the detection of enzyme substrate interaction or antibody-antigen complex that can be easily detected [79]. There are many known type of biosensors but in food industry mainly enzyme-based biosensors and immunosensors are employed. According to Amine, Mohammadi [80] the types of biosensors employed for food industries can be categorized into three kinds; (i) first being those based on cell immobilization as a whole [81-83], (ii) second based on devices that contain immobilized enzymes and attached to the reactors and (iii) thirdly being those containing transducers that depend upon direct immobilization of the enzymes being used [80]. Contaminated foods lead to the health implications, causes of which might be biological or biochemical agents or activities, for these purpose food biosensors can be very helpful in that regard. Commonly health implications are imposed by microbes (mainly bacteria and fungi) that lead to the spread of serious health hazards [84].

Bacterial monitoring: Among bacteria, common food spoiling related to health hazards include, E. coli strain 0157:H7, Listeria monocytogenes, campylobacter and salmonella. These bacteria are common problems faced by the food industries as they reduce the consumer demands of the food if the food provided by company gets contaminated with these food spoiling biological entities. Salmonella, a rod-shaped bacterium is the major cause of food poisoning, leading to excessive loss of water and salts from the body. If conditions not checked properly, might be fatal under severe cases. Food industries had been striving to get rid of the cause of food poisoning by timely detection and removal of this bacterium. For monitoring Salmonella, piezoelectric biosensors are commonly used that can detect monoclonal antigen-antibody complex quickly and easily but are poor detectors of polyclonal antibody complexes, which is its main drawback and needs to be addressed for upgradations [84]. Listeria monocytogenes bacterium is commonly found in processed meat and can grow in the food processing industries from where it gets into the newly processed foodstuffs. It can also be found raw milk or its products. They are the cause of a common disease in humans named as listeriosis. Listeriosis is just like common flu and also leads to miscarriage. According to Geng, Morgan [85], for L. monocytogenes, fibre-optic biosensors have been commonly used to monitor its presence. Surface Plasmon Resonance (SPR) biosensors along with fibre-optic biosensors have proven to be best for L. monocytogenes detection [84].Campylobacter jejuni is also the common cause of food poisoning worldwide. Optical SPR can also be used for quick detection of campylobacter [84]. E. coli strain 0157:H7 leads to the cause of bloody diarrhea and sometimes it may cause kidney failure. It is mostly present in poorly cooked foods, cheese, raw milk, juices and also in contaminated water sources etc. Amperometric biosensors based on bienzymatic system had been successfully used for the detection of E. coli 0157:H7 [86]. Before that optical sensors had also showed precise monitoring of 0157:H7.

Fungal pathogens detection: Besides bacteria fungi are also the common cause of food spoilage and causing severe health related problems that may prove to be life threatening in most cases. Fungi that cause food contamination are commonly Botrytis sp., Aspergillus, Colletotrichum and many other fungal species like that. Due to the

\begin{tabular}{|c|c|c|c|c|c|}
\hline Biosensor & Linear range & Response time & Detection limit & $\begin{array}{c}\text { Sensitivity } \\
\mu \mathrm{AmM}^{-1}\end{array}$ & References \\
\hline PANI/HRP/GE-CNT-Nafion/AuPt NPs & $17 \mu \mathrm{M}-0.1 \mathrm{mM}$ & --- & $17 \mu \mathrm{M}$ & $3.7 \times 10^{2}$ & [70] \\
\hline $\mathrm{Hb} / \mathrm{AuNPS} / \mathrm{ZnO} / \mathrm{Gr} / \mathrm{GCE}$ & $6.0-1130 \mu \mathrm{M}$ & $<2 s$ & $0.8 \mu \mathrm{M}$ & --- & [71] \\
\hline $\mathrm{Hb}-\mathrm{PpPDA} @ \mathrm{Fe}_{3} \mathrm{O}_{4} / \mathrm{GCE}$ & $0.5-400.0 \mu \mathrm{M}$ & $<4 \mathrm{~s}$ & $0.21 \mu \mathrm{M}$ & -0.076 & [72] \\
\hline $\mathrm{Hb} / 3 \mathrm{DOM}$ GTD/ITO & $5.0 \mu \mathrm{M}-1.0 \mathrm{mM}$ & --- & $0.6 \mu \mathrm{M}$ & 144.5 & [76] \\
\hline HRP_polyAuNPs-Au & $5 \mu \mathrm{M}-1.1 \mathrm{mM}$ & $8 \mathrm{~s}$ & $1.5 \mu \mathrm{M}$ & 498 & [77] \\
\hline
\end{tabular}

Table 2: Biosensors for hydrogen peroxide detection. 
remarkable specificity, reduced costs and easy and quick monitoring through biosensors, fungal toxins can be also detected using optical SPR biosensors [87-90]. After their detection, steps to remove them from food products can be taken within the time (Table 3 ).

\section{Environmental applications of biosensors}

Biological sensors that we know today in the biochemical field of science have some great potential for detecting and monitoring the interaction of biological molecules inside and outside the cells. These sensors have provided easiness to the scientists of today in overcoming the undetectable levels of many harmful agents that would have otherwise remained undetected. Here, in the applications section of biosensors, some recent studies have been compiled to give an overall background of the most recent advantages that biosensors have provided in monitoring many harmful environmental agents that are responsible for the cause of some serious health hazards to humans and the ecosystem. In order to avoid hazards to human health and to the surroundings, a mechanism to understand, detect and remove the contaminants from the surroundings, like water, soil and air within affordable costs, quite quickly and with enhanced precision must be have to be adopted today and this can be achieved using the biosensing techniques. Different types of biosensors based on enzymatic inhibition and those based on DNA with high specificity to certain DNA, RNA or proteins that they can encounter have been used for the removal of contaminants like, pesticides, other toxins and heavy metals from soil, air and water including many other versatile types of biosensors. Sensors which are based on screen-printed electrodes [91,92] are widely being used by the biosensor industries to construct the biosensors for their increasing needs by food industries, environmental and medical departments. Another type of biosensors called phage sensors has been developed to monitor pathogens and contaminants in food and environment [93]. The major pollutant that can be successively detected and removed using biosensors includes heavy metals, polychlorinated biphenyls, pesticides, Biochemical Oxygen Demand (BOD), nitrogenous compounds and various pathogens (including many viruses and bacteria).

Heavy metals: Heavy metals pose maximum threat to health of humans and their hyper-accumulation leads to various inappropriate health conditions, as they cannot be easily biodegraded [94]. Several types of biosensors have provided great success in detection and monitoring of the toxic levels of heavy metals that would lead to injurious health conditions. Bacteria-based cell biosensors requires the use of genes that resist certain types of heavy metals like copper, mercury, tin cobalt etc. $[95,96]$. However, they can act when the heavy metals interact with their cytoplasm, dependence of these sensors is based on the conjugation of some luminescent proteins like luciferin, with those genes that resist heavy metals [94]. Enzyme-based biosensors have also provided promising results in that regard, like fibre-optic biosensors have been used for the detection of the toxic levels of various heavy metals like lead, cadmium, mercury, copper, nickel, cobalt etc. These biosensors work by inhibition of these heavy metals by metal ions on various kinds of enzymes, these inhibitions are then monitored by using different types of biosensors with HIGH specificity. Amperometric biosensors were used for the successful detection of inhibition of mercury ions $\left(\mathrm{Hg}^{+2}\right)$ by urease enzyme action [97]. Inhibition of cobalt, nickel, mercury, gold and lead with same urease enzyme lead to the monitoring of the toxic levels using fibreoptic sensors [98].

Polychlorinated biphenyls (PCBs): Polychlorinated biphenyls are non-biodegradable agents used in various types of herbicides and insecticides that though prove to be good for pest control but also lead to the accumulation of these PCBs in the soil which are then taken up by the crops and in turn they enter human body and causes serious health problems, most of the times related to cancers. Biosensors have been most promising in the past years in precise detection of these organic compounds in foods and soils, using immunological biosensors that monitors antigen-antibo35dy interaction using piezoelectric transducers $[99,100]$

BODs: Microorganisms that live in sewers and waste waters usually break down organic compounds to produce toxic substances. Biochemical oxygen demand (BOD) is the amount of molecular oxygen $\left(\mathrm{O}_{2}\right)$ required by microorganisms to thrive in waste water and is mostly required during break down of organic compounds [94,101103]. This leads to the increased environmental pollution in water sources. A biosensor was developed by Nisshin Denki Electric Co. Ltd. in 1983 and was the first ever made commercial biosensor for BOD level monitoring [103].

Pesticides: Organophosphates being commonly used as insecticides (pesticides) pose changes to the soil fertility, thus damaging many beneficial insects and microbes in soil and leads to the loss of biodiversity, for their detection, another type of nanotechnological sensors have been used recently to measure toxic levels of these pesticides in soils and in water. Based on nanotechnology, enzymaticbiosensors have been modified by allowing them to be immobilized. The common example is of acetylcholinesterase (enzyme) sensors which work by inhibiting acetylcholinesterase activity in order to detect organophosphates, where acetylcholinesterase activity is constantly monitored [102].

Nitrogen compounds and microbial detection: Commercial biosensors have also been introduced and used successfully to monitor dioxins, nitrates and E. coli and dioxin-like compounds [103]. Microbes-based biosensors can also be employed for monitoring airborne contaminants and also pathogens. Phage-sensors can be used for detecting air-borne pathogenic microbes [93] (Table 4).

\section{Conclusion}

One of the major hurdles in the biosensor development is the use of synthetic biological agents and cell surface receptors like antibodies, nucleic acids, enzymes etc. These synthetic receptors are not easily

\begin{tabular}{|c|c|c|c|c|}
\hline Bacteria & Types of biosensors & Found in foods & Detection range/limit & References \\
\hline Salmonella & Piezoelectric & Eggs, meat, raw milk, meat and dairy products. & $1.7 \times 10^{2} \mathrm{cells} / \mathrm{mL}$ & [88] \\
\hline \multirow{2}{*}{$\begin{array}{l}\text { L.monocytogenes (pure } \\
\text { culture) }\end{array}$} & Fibre-optic & \multirow[t]{2}{*}{ Raw milk, meat, milk products. } & $10^{7}$ to $10^{8} \mathrm{CFU} / \mathrm{mL}$ & [85] \\
\hline & SPR sensor & & $\begin{array}{l}\text { low concentrations upto } 10^{5} \\
\text { CFU/mL }\end{array}$ & [89] \\
\hline $\begin{array}{c}\text { C. jejuni } \\
\text { (pure culture) }\end{array}$ & SPR sensor & Raw milk, uncooked chicken, contaminated water. & $10^{1}$ to $10^{8} \mathrm{CFU} / \mathrm{mL}$ & [90] \\
\hline E. coli O157:H7 & Amperometric & Raw milk, milk products, juices, cheese etc. & $1.0 \times 10^{7} \mathrm{cells} / \mathrm{mL}$ & {$[86]$} \\
\hline
\end{tabular}

Table 3: Biosensors for detection of various types of bacteria that spoil food and cause harms to human health with their detection ranges. 
Citation: Ali J, Najeeb J, Ali MA, Aslam MF, Raza A (2017) Biosensors: Their Fundamentals, Designs, Types and Most Recent Impactful Applications: A Review. J Biosens Bioelectron 8: 235. doi: 10.4172/2155-6210.1000235

Page 7 of 9

\begin{tabular}{|c|c|c|c|}
\hline Pollutants & Biosensors & Detectability source & References \\
\hline \multirow[t]{3}{*}{ Heavy metals ( $\mathrm{Hg}, \mathrm{Cd}, \mathrm{Ni}, \mathrm{Co}, \mathrm{Zn}, \mathrm{Cu}, \mathrm{Pb}, \mathrm{Au}, \mathrm{Pb}, \mathrm{Cu})$} & Bacterial-based sensors & \multirow[t]{3}{*}{ Soil, sewage water } & [95] \\
\hline & Amperometric (Ureases enzyme-based) for $\mathrm{Hg}$ & & [97] \\
\hline & Optical sensor & & [98] \\
\hline PCBs & Piezoelectric immuno-sensor & $\begin{array}{l}\text { Soil, water and various foods } \\
\text { (fruits, vegetables) }\end{array}$ & [99] \\
\hline BODs & Optical sensor & Contaminated, waste waters & [100] \\
\hline Nitrogenous Compounds & Ezyme-based conductimetric sensor & Natural water sources & [101] \\
\hline Organophosphates (Pesticides) & Enzymatic sensors (Acetylcholinesterase based) & Soils, water sources & [102] \\
\hline
\end{tabular}

Table 4: Biosensors for various environmental pollutants.

identified and are thus not allowed by the cell to cross the lipid bilayer. For biosensors to function properly they must get entry into the cells. Research work on biological agents could lead to the development of new biosensors that would have potential benefits to the wellbeing of humans. Nanotechnology plays a pivotal role in that regard as nanomaterials particularly in the form of quantum dots could be modified using receptor elements to detect certain types of tumors and at the same time after detection, they may have the ability to deliver drugs to the tumors. Once all developmental hurdles will be overcome, then it would be a great success in the history of mankind, although it is being used, yet its success percentage still needs to be upgraded. With such good and precise delectability within less time, reduced costs and high specificity to certain microbes, proteins and other related bioelement and biomolecules, biosensors have proved to be the best equipment for the detection of certain agents that would otherwise cause harm to human health. Recent advances in the biosensors development over the past few years have paved the way for future researchers to further modify these biosensing elements to enhance them to the extent that would be able to detect even most dangerous diseases like most of the viral diseases (HCV, HIV, Ebola, CrimeanCongo Virus, Rabies etc.) and not only in humans but also viral diseases related to plants. Moreover these sensing agents can also be employed for bioremediation of pollutants from the areas where most of the problems occur due to pollution leading to unhealthy conditions affecting ecosystem in a negative manner.

\section{Acknowledgements}

hereby thank my co-author who contributed a lot in completing this review, although we have no funding sources neither any financial support. It is a combined effort of both of us to give this review a finalized shape of originality. We have worked hard to create this review just to comfort the fresh scientists to get benefit from this compiled information about biosensors from the recent years.

\section{References}

1. Buenger D, Topuz F, Groll J (2012) Hydrogels in sensing applications. Progress in Polymer Science 37: 1678-1719.

2. Yuriyama M, Kushida T (2010) Sensor-cloud infrastructure-physical sensor management with virtualized sensors on cloud computing. In Network-Based Information Systems (NBiS), 13th International Conference on IEEE.

3. McQuade DT, Pullen AE, Swager TM (2000) Conjugated polymer-based chemical sensors. Chemical Reviews 100: 2537-2574.

4. Yogeswaran U, Chen SM (2008) A review on the electrochemical sensors and biosensors composed of nanowires as sensing material. Sensors 2008 8: 290-313.

5. Gordeliy VI (2002) Molecular basis of transmembrane signalling by sensory rhodopsin II-transducer complex. Nature 419: 484-487.

6. Lenz J, Edelstein S (2006) Magnetic sensors and their applications. IEEE Sensors journal 6: 631-649.

7. Picerno $P$ (2016) 25 years of lower limb joint kinematics by using inertial and magnetic sensors: a review of methodological approaches. Gait \& Posture 51 239-246

8. Zhu R, Zhou Z (2004) A real-time articulated human motion tracking using tri- axis inertial/magnetic sensors package. IEEE Transactions on Neural systems and rehabilitation engineering 12: 295-302.

9. Buryakov IT, Buryakov, Matsayev V (2016) Electrical, electrochemical, and thermometric sensors for the detection of explosives. Journal of Analytical Chemistry 71 : 234-242.

10. Cao S (2016) Robust and Stable Ratiometric Temperature Sensor Based on $\mathrm{Zn}-\mathrm{In}-\mathrm{S}$ Quantum Dots with Intrinsic Dual-Dopant Ion Emissions. Advanced Functional Materials 26: 7224-7233.

11. Liu J, Van Deun R, Kaczmarek AM (2016) Optical thermometry of MoS 2: Eu 3+ 2D luminescent nanosheets. Journal of Materials Chemistry C 4: 9937-9941.

12. Akkaya OC (2016) Apparatus and methods utilizing optical sensors operating in the reflection mode, Google Patents.

13. Baro JA (2016) Biofilm monitoring of dissolved oxygen in wine aging barre wood with optical chemical sensors. In Instrumentation and Measurement Technology Conference Proceedings (I2MTC), 2016 IEEE International, IEEE.

14. Cucinotta A (2016) Optical Fiber Sensors for Label-free DNA Detection. Optical Sensors, Optical Society of America.

15. Mahmud A (2016) Flexible Ag-ChG Radiation Sensors: Limit of Detection and Dynamic Range Optimization through Physical Design Tuning. IEEE Transactions on Nuclear Science 63: 2137-2144.

16. Mollenhauer H (2016) Adaptive Multichannel Radiation Sensors for Plant Parameter Monitoring. In EGU General Assembly Conference Abstracts.

17. Singh N (2016) Design and growth of novel compounds for radiation sensors: Multinary chalcogenides. In SPIE Defense+Security, International Society for Optics and Photonics.

18. Huang $L$ (2016) Electrical gas sensors based on structured organic ultra-thin films and nanocrystals on solid state substrates. Nanoscale Horizons.

19. Schultz J (2016) Irrigated ablation catheter with multiple sensors. US Patent pp: 1-8.

20. Yang Z, Dou X (2016) Emerging and Future Possible Strategies for Enhancing 1D Inorganic Nanomaterials-Based Electrical Sensors towards Explosives Vapors Detection. Advanced Functional Materials.

21. Fojta M (2016) Recent progress in electrochemical sensors and assays for DNA damage and repair. TRAC 79: 160-167.

22. Xiao F, Wang L, Duan H (2016) Nanomaterial based electrochemical sensors for in vitro detection of small molecule metabolites. Biotechnology Advances 34: $234-249$

23. Wang J (2006) Zinc oxide nanocomb biosensor for glucose detection. Applied Physics Letters 88: 3106

24. Ibraheem A, Campbell RE (2010) Designs and applications of fluorescent protein-based biosensors. Current Opinion in Chemical Biology 14: 30-36

25. Hinze S (1994) Bibliographical cartography of an emerging interdisciplinary discipline: The case of bioelectronics. Scientometrics 29: 353-376.

26. Palmer AE (2011) Design and application of genetically encoded biosensors Trends in Biotechnology 29: 144-152.

27. Situ C (2010) Advances in surface plasmon resonance biosensor technology towards high-throughput, food-safety analysis. TRAC 29: 1305-1315.

28. Tamayo J (2001) Chemical sensors and biosensors in liquid environment based on microcantilevers with amplified quality factor. Ultramicroscopy 86: 167-173. 
Citation: Ali J, Najeeb J, Ali MA, Aslam MF, Raza A (2017) Biosensors: Their Fundamentals, Designs, Types and Most Recent Impactful Applications: A Review. J Biosens Bioelectron 8: 235. doi: 10.4172/2155-6210.1000235

29. Edelstein $R$ (2000) The BARC biosensor applied to the detection of biological warfare agents. Biosensors and Bioelectronics 14: 805-813

30. Clark LC, Lyons C (1962) Electrode systems for continuous monitoring in cardiovascular surgery. Annals of the New York Academy of sciences 102 $29-45$

31. Chao J, Zhu D, Zhang Y, Wang L, Fan C (2016) DNA nanotechnology-enabled biosensors. Biosensors and Bioelectronics 76: 68-79.

32. Vidal JC (2013) Electrochemical affinity biosensors for detection of mycotoxins: A review. Biosensors and Bioelectronics 49: 146-158.

33. Kahn K, Plaxco KW (2010) Principles of biomolecular recognition. In Recognition Receptors in Biosensors pp: 3-45.

34. Marx K., (2007) Toward understanding the intelligent properties of biological macromolecules-implications for their design into biosensors. Smart Biosensor Technology, Marcel Dekker, New York pp: 3-82.

35. Doretti L (2000) Acetylcholine biosensor involving entrapment of acetylcholinesterase and poly (ethylene glycol)-modified choline oxidase in a poly (vinyl alcohol) cryogel membrane. Enzyme and Microbial Technology 27: 279-285

36. Wang J, Musameh M (2005) Carbon-nanotubes doped polypyrrole glucose biosensor. Analytica Chimica Acta 539: 209-213.

37. Gupta R, Chaudhury N (2007) Entrapment of biomolecules in sol-gel matrix for applications in biosensors: Problems and future prospects. Biosensors and Bioelectronics 22: 2387-2399.

38. Bisht V, Takashima W, Kaneto K, (2005) An amperometric urea biosensor based on covalent immobilization of urease onto an electrochemically prepared copolymer poly (N-3-aminopropyl pyrrole-co-pyrrole) film. Biomaterials 26 : 3683-3690.

39. Monošík R, Stred'anský M, Šturdík E (2012) Biosensors-classification, characterization and new trends. Acta Chimica Slovaca 5: 109-120.

40. Thévenot DR, Toth K, Durst RA, Wilson GS (2001) Electrochemical biosensors: Recommended definitions and classification. Biosensors and Bioelectronics 16: 121-131.

41. Mohanty SP, Kougianos E (2006) Biosensors: a tutorial review. IEEE Potentials 25: $35-40$.

42. Turner AP (2000) Biosensors--sense and sensitivity. Science 290: 1315-1317.

43. Fu G, Yue X, Dai Z (2011) Glucose biosensor based on covalent immobilization of enzyme in sol-gel composite film combined with Prussian blue/carbon nanotubes hybrid. Biosensors and Bioelectronics 26: 3973-3976.

44. Unnikrishnan B, Palanisamy S, Chen SM (2013) A simple electrochemical approach to fabricate a glucose biosensor based on graphene-glucose oxidase biocomposite. Biosensors and Bioelectronics 39: 70-75.

45. Zhang $H$ (2011) A novel glucose biosensor based on direct electrochemistry of glucose oxidase incorporated in biomediated gold nanoparticles-carbon nanotubes composite film. Sensors and Actuators B: Chemical 158: 23-27.

46. Zheng B (2011) Gold nanoparticles-coated eggshell membrane with immobilized glucose oxidase for fabrication of glucose biosensor. Sensors and Actuators B: Chemical 152: 49-55.

47. Yang Z (2014) Potentiometric glucose biosensor based on core-shell Fe 30 4-enzyme-polypyrrole nanoparticles. Biosensors and Bioelectronics 51: 268-273.

48. Zeng Q (2011) Palladium nanoparticle/chitosan-grafted graphene nanocomposites for construction of a glucose biosensor. Biosensors and Bioelectronics 26: 3456-3463.

49. Qiu JD, Huang J, Liang RP (2011) Nanocomposite film based on graphene oxide for high performance flexible glucose biosensor. Sensors and Actuators B: Chemical 160: 287-294.

50. Fang $B$ (2011) A glucose oxidase immobilization platform for glucose biosensor using ZnO hollow nanospheres. Sensors and Actuators B: Chemical 155: 304-310.

51. Si P (2011) Highly stable and sensitive glucose biosensor based on covalently assembled high density Au nanostructures. Biosensors and Bioelectronics 26: 3845-3851.

52. Wang L (2013) Amperometric glucose biosensor based on silver nanowires and glucose oxidase. Sensors and Actuators B: Chemical 176: 9-14.
53. Patil D (2012) Enzymatic glucose biosensor based on $\mathrm{CeO}_{2}$ nanorods synthesized by non-isothermal precipitation. Biosensors and Bioelectronics 31 176-181.

54. Hoshino T, Sekiguchi S, Muguruma H (2012) Amperometric biosensor based on multilayer containing carbon nanotube, plasma-polymerized film electron transfer mediator phenothiazine, and glucose dehydrogenase. Bioelectrochemistry $84: 1-5$.

55. Liang B (2013) Microbial surface display of glucose dehydrogenase for amperometric glucose biosensor. Biosensors and Bioelectronics 45: 19-24.

56. Hasan A (2014) Recent advances in application of biosensors in tissue engineering. BioMed Research International pp: 1-18.

57. Homola J (2003) Present and future of surface plasmon resonance biosensors. Analytical and Bioanalytical Chemistry 377: 528-539.

58. Ozsoz MS (2012) Electrochemical DNA biosensors. CRC Press.

59. Candiani, A (2013) Label-free DNA biosensor based on a peptide nucleic acid-functionalized microstructured optical fiber-Bragg grating. Journal of Biomedical Optics 18: 057004-057004.

60. Bo Y (2011) A novel electrochemical DNA biosensor based on graphene and polyaniline nanowires. Electrochimica Acta 56: 2676-2681.

61. Li F, Han X, Liu S (2011) Development of an electrochemical DNA biosensor with a high sensitivity of $\mathrm{fM}$ by dendritic gold nanostructure modified electrode. Biosensors and Bioelectronics 26: 2619-2625.

62. Chen J (2011) An ultrasensitive electrochemical biosensor for detection of DNA species related to oral cancer based on nuclease-assisted target recycling and amplification of DNAzyme. Chemical Communications 47: 8004-8006.

63. Bo Y (2011) A DNA biosensor based on graphene paste electrode modified with Prussian blue and chitosan. Analyst 136: 1946-1951.

64. Luo C (2013) A sensitive electrochemical DNA biosensor for specific detection of Enterobacteriaceae bacteria by Exonuclease III-assisted signal amplification. Biosensors and Bioelectronics 48: 132-137.

65. Wang Q (2011) Hybridization biosensor based on the covalent immobilization of probe DNA on chitosan-mutiwalled carbon nanotubes nanocomposite by using glutaraldehyde as an arm linker. Sensors and Actuators B: Chemical 156: 599-605.

66. Yola ML, Eren T, Atar N (2014) A novel and sensitive electrochemical DNA biosensor based on Fe@ Au nanoparticles decorated graphene oxide. Electrochimica Acta 125: 38-47.

67. Zhang Y (2013) A novel graphene-DNA biosensor for selective detection of mercury ions. Biosensors and Bioelectronics 48: 180-187.

68. Rad AS, Mirabi A, Binaian E, Tayebi H (2011) A review on glucose and hydrogen peroxide biosensor based on modified electrode included silver nanoparticles. Int J Electrochem Sci 6: 3671-3683

69. Wang W (2011) Amperometric hydrogen peroxide biosensor based on the immobilization of heme proteins on gold nanoparticles-bacteria cellulose nanofibers nanocomposite. Talanta 84: 71-77.

70. Sheng Q, Wang M, Zheng J (2011) A novel hydrogen peroxide biosensor based on enzymatically induced deposition of polyaniline on the functionalized graphene-carbon nanotube hybrid materials. Sensors and Actuators B: Chemical 160: 1070-1077.

71. Xie L, Xu Y, Cao X (2013) Hydrogen peroxide biosensor based on hemoglobin immobilized at graphene, flower-like zinc oxide, and gold nanoparticles nanocomposite modified glassy carbon electrode. Colloids and Surfaces B: Biointerfaces 107: 245-250.

72. Baghayeri M, Zare EN, Lakouraj MM (2014) A simple hydrogen peroxide biosensor based on a novel electro-magnetic poly (p-phenylenediamine) @ $\mathrm{Fe}_{3} \mathrm{O}_{4}$ nanocomposite. Biosensors and Bioelectronics 55: 259-265.

73. Zhiguo G (2011) An ultrasensitive hydrogen peroxide biosensor based on electrocatalytic synergy of graphene-gold nanocomposite, CdTe-CdS coreshell quantum dots and gold nanoparticles. Analytica Chimica Acta 701: 75-80.

74. Li S (2012) Hydrogen peroxide biosensor based on gold nanoparticles/thionine/ gold nanoparticles/multi-walled carbon nanotubes-chitosans composite filmmodified electrode. Applied Surface Science 258: 2802-2807.

75. Xuan J (2012) Gold nanoparticle-assembled capsules and their application as 
Citation: Ali J, Najeeb J, Ali MA, Aslam MF, Raza A (2017) Biosensors: Their Fundamentals, Designs, Types and Most Recent Impactful Applications: A Review. J Biosens Bioelectron 8: 235. doi: 10.4172/2155-6210.1000235

Page 9 of 9

hydrogen peroxide biosensor based on hemoglobin. Bioelectrochemistry 84 : 32-37.

76. Wei N (2011) A novel hydrogen peroxide biosensor based on the immobilization of hemoglobin on three-dimensionally ordered macroporous (3DOM) goldnanoparticle-doped titanium dioxide (GTD) film. Biosensors and Bioelectronics 26: 3602-3607.

77. Villalonga $R$ (2011) Wiring horseradish peroxidase on gold nanoparticlesbased nanostructured polymeric network for the construction of mediatorless hydrogen peroxide biosensor. Electrochimica Acta 56: 4672-4677.

78. Luong JH, Bouvrette P, Male KB (1997) Developments and applications of biosensors in food analysis. Trends in Biotechnology 15: 369-377.

79. Terry LA, White SF, Tigwell LJ (2005) The application of biosensors to fresh produce and the wider food industry. Journal of Agricultural and Food Chemistry 53: $1309-1316$

80. Amine A (2006) Enzyme inhibition-based biosensors for food safety and environmental monitoring. Biosensors and Bioelectronics 21: 1405-1423.

81. Chouteau C (2005) A bi-enzymatic whole cell conductometric biosensor for heavy metal ions and pesticides detection in water samples. Biosensors and Bioelectronics 21: 273-281.

82. Durrieu C (2004) A bi-enzymatic whole-cell algal biosensor for monitoring waste water pollutants. Analytical Letters 37: 1589-1599.

83. Rekha K (2000) Ascorbate oxidase based amperometric biosensor for organophosphorous pesticide monitoring. Biosensors and Bioelectronics 15: 499-502.

84. Serna-Cock L, Perenguez-Verdugo JG (2011) Biosensors applications in agrifood industry. INTECH Open Access Publisher.

85. Geng T, Morgan MT, Bhunia AK (2004) Detection of low levels of Listeria monocytogenes cells by using a fiber-optic immunosensor. Applied and Environmental Microbiology 70: 6138-6146.

86. Tang $H$ (2006) A new amperometric method for rapid detection of Escherichia coli density using a self-assembled monolayer-based bienzyme biosensor. Analytica Chimica Acta 562: 190-196.

87. Li Y, Liu X, Lin Z (2012) Recent developments and applications of surface plasmon resonance biosensors for the detection of mycotoxins in foodstuffs. Food Chemistry 132: 1549-1554.

88. Fung $Y$, Wong $Y$ (2001) Self-assembled monolayers as the coating in a quartz piezoelectric crystal immunosensor to detect Salmonella in aqueous solution. Analytical Chemistry 73: 5302-5309.

89. Leonard P Hearty S, Quinn J, O'Kennedy R (2004) A generic approach for the detection of whole Listeria monocytogenes cells in contaminated samples using surface plasmon resonance. Biosensors and Bioelectronics 19: 1331 1335.

90. Wei D (2007) Development of a surface plasmon resonance biosensor for the identification of Campylobacter jejuni. Journal of Microbiological Methods 69: 78-85.

91. Tudorache M, Bala C (2007) Biosensors based on screen-printing technology and their applications in environmental and food analysis. Analytical and Bioanalytical Chemistry 388: 565-578.

92. Hayat A, Marty JL (2014) Disposable screen printed electrochemical sensors: Tools for environmental monitoring. Sensors 14: 10432-10453.

93. Van Dorst B Mehta J, Bekaert K, Rouah-Martin E, De Coen W, et al (2010) Recent advances in recognition elements of food and environmental biosensors: A review. Biosensors and Bioelectronics 26: 1178-1194.

94. da Costa Silva LM, Melo AF, Salgado AM (2004) Biosensors for Environmenta Applications. Pure Appl Chem 76: 723-752.

95. Magrisso S, Erel Y, Belkin S (2008) Microbial reporters of metal bioavailability. Microbial Biotechnology 1: 320-330.

96. Rathnayake I (2009) Tolerance of heavy metals by gram positive soil bacteria World Academy of Science Engineering and Technology.

97. Domínguez-Renedo O (2009) Development of urease based amperometric biosensors for the inhibitive determination of $\mathrm{Hg}$ (II). Talanta 79: 1306-1310.

98. Kuswandi B (2003) Simple optical fibre biosensor based on immobilised enzyme for monitoring of trace heavy metal ions. Analytical and Bioanalytical Chemistry 376: 1104-1110.

99. Přibyl J, Hepel M, Skládal P (2006) Piezoelectric immunosensors for polychlorinated biphenyls operating in aqueous and organic phases. Sensors and Actuators B: Chemical 113: 900-910.

100. Ivask A, Virta M, Kahru A (2002) Construction and use of specific luminescent recombinant bacterial sensors for the assessment of bioavailable fraction of cadmium, zinc, mercury and chromium in the soil. Soil Biology and Biochemistry 34: 1439-1447.

101. Khadro B (2008) Enzymatic conductometric biosensor based on PVC membrane containing methyl viologen/nafion $₫ /$ nitrate reductase for determination of nitrate in natural water samples. Sens Mater 20: 267-279.

102.Zhang W (2014) Nanomaterial-based biosensors for environmental and biological monitoring of organophosphorus pesticides and nerve agents. TRAC 54: 1-10.

103. Bahadır EB, Sezgintürk MK (2015) Applications of commercial biosensors in clinical, food, environmental, and biothreat/biowarfare analyses. Analytical Biochemistry 478: 107-120. 